Article

\title{
PEDOT:PSS in Water and Toluene for Organic Devices-Technical Approach
}

\author{
Beata Jewłoszewicz ${ }^{\mathbb{D}}$, Krzysztof A. Bogdanowicz * ${ }^{\mathbb{D}}$, Wojciech Przybył ${ }^{\mathbb{D}}$, Agnieszka Iwan and \\ Ireneusz Plebankiewicz
}

Military Institute of Engineer Technology, Obornicka 136 Str., 50-961 Wroclaw, Poland; jewloszewicz@witi.wroc.pl (B.J.); przybyl@witi.wroc.pl (W.P.); iwan@witi.wroc.pl (A.I.); plebankiewicz@witi.wroc.pl (I.P.)

* Correspondence: bogdanowicz@witi.wroc.pl

Received: 16 February 2020; Accepted: 24 February 2020; Published: 4 March 2020

check for updates

\begin{abstract}
Poly(3,4-ethylenedioxythiophene:poly(styrenesulfonate) (PEDOT:PSS) water and toluene solutions were investigated in detail, taking into consideration their stability, wettability, transparency, and electrochemical properties, along with change polarity caused by dopant. As dopant, methanol, ethanol, and isopropanol were used with different dipole moments (1.70, 1.69, and 1.66 D) and dielectric constants (33.0, 24.5, and 18.0). Three techniques, i.e., spin coating, doctor blade coating, and spray coating, were employed to created PEDOT:PSS layers on glass, glass/indium tin oxide (ITO), and glass/fluorine-doped tin oxide (FTO) substrates with optimized technical parameters for each used equipment. All used PEDOT:PSS water and toluene solutions demonstrated good wetting properties with angles below $30^{\circ}$ for all used surfaces. Values of the energy bandgap (Eg) of PEDOT:PSS investigated by cyclic voltammetry (CV) in solution showed increase energy Eg along with addition of alcohol to the mixture, and they were found in the range of $1.20 \mathrm{eV}$ to $2.85 \mathrm{eV}$. The opposite tendency was found for the Eg value of the PEDOT:PSS layer created from water solution. The storage effect on PEDOT:PSS layers detected by CV affected only the lowest unoccupied molecular orbital (LUMO) level, thereby causing changes in the energy bandgap. Finally, simple devices were constructed and investigated by infrared (IR) thermographic camera to investigate the surface defects on the created PEDOT:PSS layers. Our study showed that a more stable PEDOT:PSS layer without pin-holes and defects can be obtained from water and toluene solutions with isopropanol via the spin coating technique with an optimal speed of $3000 \mathrm{rpm}$ and time of $90 \mathrm{~s}$.
\end{abstract}

Keywords: PEDOT:PSS; organic devices; spin coating; doctor blade coating; spray coating; thermographic camera

\section{Introduction}

In recent years, increased interest in organic devices, such as solar cells (SCs), was observed in both academia and industry, focusing on high efficiency and solution-based fabrication [1-3]. Comparing different configurations of polymer solar cells (PSCs), a classification into mesoscopic (n-i-p) PSCs, planar (n-i-p) PSCs, and inverted planar (p-i-n) PSCs can be made [4-6]. Considering the typical planar architecture, the addition of a mesoscopic layer complicates the manufacture process, while also requiring a high-temperature sintering operation, which is not compatible with polymer-based flexible substrates [7]. Hence, the currently trending roll-to-roll industrially available mass production of planar or inverted planar SCs could benefit from flexible and low-temperature solution processes [8].

Flexible and low-temperature processes are needed to create transparent electrodes, which are important for many optoelectronic devices, i.e., touch screens, organic light-emitting diodes, and solar cells [7]. A transparent and flexible electrode should possess some characteristics such as optical 
transparency, high conductivity, and, in some cases, a high level of bending toughness without a significant decrease in electrical performance. A golden balance needs to be found between the electrical resistivity and transmittance, since good conductivity does not align well with transparency. At the moment, commercial transparent electrodes are based mainly on indium tin oxide (ITO). However, its poor mechanical properties, its relatively low conductivity in flexible transparent electrodes, and the scarcity of indium necessitate the search for a new generation of optoelectronic devices [9].

Generally, strategies for the preparation of flexible transparent electrodes can be classified as follows:

(1) conducting polymers (e.g., poly(3,4-ethylenedioxythiophene:poly(styrenesulfonate) (PEDOT:PSS), polyaniline (PANI), polypyrrole (PPy)) [10-12];

(2) inorganic nanostructures (e.g., carbon nanotubes, graphene, metal nanowires) [13-16];

(3) hybrid materials (e.g., single-walled carbon nanotubes, L,D-PLA, PANI nanowire/nylon nanofiber) $[17,18]$.

In organic devices, other layers in addition to the electrodes should also possess good flexibility and transparency. It is well known that PEDOT:PSS can act as a transparent electrode in devices, while it can also play the role of a hole transporting layer (HTL) in organic solar cells, taking into consideration its high work function, high transparency, and good conductivity. Unfortunately, PEDOT:PSS in organic solar cells exhibits various disadvantages when it comes to HTL formation, with a consequent decrease in the long-term stability and performance of devices [19]. The main disadvantages are as follows: (i) aggregation of particles in a water solution of PEDOT:PSS, (ii) degradation of ITO surface, (iii) instability of the ITO/PEDOT:PSS interface in devices due to strong acid characteristics of PSS in PEDOT:PSS, (iv) hydrophilic characteristics of PEDOT:PSS solution, and (v) instability of PEDOT:PSS in water in a short time.

To solve these difficulties, various inorganic compounds such as $\mathrm{V}_{2} \mathrm{O}_{5}, \mathrm{WO}_{3}, \mathrm{NiO}$, and $\mathrm{MoO}_{3}$ were proposed instead of PEDOT:PSS applied in organic solar cells [20]. Organic compounds used as HTLs in organic solar cells mainly include poly(styrene sulfonic acid) grafted with polyaniline (PSSA-g-PANI) [19], polypyrrole-polystyrene sulfonate (PPy:PSS) [21], PEDOT:PSS and amphiphilic surfactant Surfynol 104 series [20], PEDOT:PSS with mixed Ag and Au nanoparticles (dual NPs) [22], or a new polymer with carbazole and $\mathrm{PO}_{3}$ moieties (PC-P) [23].

In recent years, poly(3,4-ethylenedioxythiophene:poly(styrenesulfonate) (PEDOT:PSS), especially with regard to its use in electronic devices including photovoltaics, received interest on account of its relatively simple processability at low temperature, antireflecting properties, and water-based dispersion [24-27]. In some devices, water-free PEDOT:PSS is required, mainly due to the design of the layer deposition process via evaporation from toluene solution or the vulnerability of some components to moisture, i.e., in the construction of perovskite solar cells [28-30].

PEDOT:PSS can be also used as a hybrid electrode over ITO or fluorine-doped tin oxide (FTO) giving improved electrical properties and mechanical support [31-33], or acting as a hole transporting layer (HTL) in dye sensitizing and perovskite solar cells [34,35].

PEDOT:PSS was investigated in the past taking into consideration both molecular and supramolecular engineering concepts. In this study, we would like to present a technical approach in the preparation of PEDOT:PSS layers for organic devices via an investigation of layer formation via spin coating, doctor blade coating, and spray coating techniques. Our main focus was on the comparison of different PEDOT:PSS solutions based on pure solvents like water or toluene and their mixtures with different alcohols such as methanol, ethanol, and isopropanol. In this article, we evaluate the electrical, thermal, and electrochemical properties of thin PEDOT:PSS layers over three different substrates (glass, glass/ITO, and glass/FTO) in order to assess the influence of alcohol adjuncts on conductive polymers. As a substrate, we tested glass with ITO or FTO, taking into consideration the fact that, depending on the type of organic solar cells, ITO or FTO substrate is mainly used. In organic/polymer solar cells, ITO 
substrate is mainly used. In DSSCs, FTO substrate is mainly used, while, in perovskite solar cells, both ITO and FTO were tested to find the best conductive substrate.

In our work, for the first time, a thermographic camera was used to detect the location of defects in the created devices, as well as to determine the electrical behavior of PEDOT:PSS and its mixture with alcohols.

In this work, we tested commercially available PEDOT:PSS in water or toluene solution. Our aim was to investigate how three alcohols with different polarity can influence the selected properties of PEDOT:PSS, taking into consideration a ternary component solution. As alcohols, methanol, ethanol, and isopropanol were used with different dipole moments $(1.70,1.69$, and $1.66 \mathrm{D})$ and dielectric constants (33.0, 24.5, and 18.0). Our study showed that the presence of isopropanol with a lower dipole moment and lower dielectric constant in PEDOT:PSS solution used for layer preparation caused an almost two-fold increase in the electrical resistance and a $30{ }^{\circ} \mathrm{C}$ decrease in the thermal response.

\section{Materials and Methods}

\subsection{Materials}

All chemical reagents and substrates were purchased from a commercial source. The mainly used components were a PEDOT:PSS (0.5:0.8 weight ratio) aqueous dispersion with a solid content of $1.3 \mathrm{wt} . \%$ (Sigma-Aldrich, Saint Louis, MO, USA), PEDOT:PSS dispersion in toluene with a solid content of 1.5 to $2.5 \mathrm{wt}$ \% (M125 HTL Solar 3, Ossila, Sheffield, UK), and high-purity alcohols, such as methanol, ethanol, and isopropanol. To study PEDOT:PSS layers, we used the following substrates: glass, FTO- and ITO-coated glass. Microscope slides $(20 \times 20 \times 1 \mathrm{~mm}$, ChemLand, Stargard Szczecinski, Poland ) were used for UV-Vis spectrometry. For FTO $(20 \times 15 \times 2.2 \mathrm{~mm}$, unpatterned, Ossila, Sheffield, UK), we used cyclic voltammetry for the electrochemical study with an IR thermographic camera ITO $(20 \times 15 \times 1.1 \mathrm{~mm}$, edgeless 8 pixel, Ossila, Sheffield, UK).

\subsection{Preparation of PEDOT:PSS Solutions}

PEDOT:PSS solutions dispersed in water or toluene were mixed with three different alcohols, methanol, ethanol, or isopropanol with volume ratio of 1:0.5. All mixtures were ultrasonicated for $1 \mathrm{~h}$ at room temperature. PEDOT:PSS mixtures in toluene with methanol and ethanol were unstable after $30 \mathrm{~min}$, at which point they stratified (Figure 1A). For these reasons, we investigated in detail only four mixtures: PEDOT:PSS in water with all three alcohols and PEDOT:PSS in toluene with isopropanol (Figure 1B). All mixtures were prepared for tests directly before film application, while, for aging tests, they were stored in the fridge.
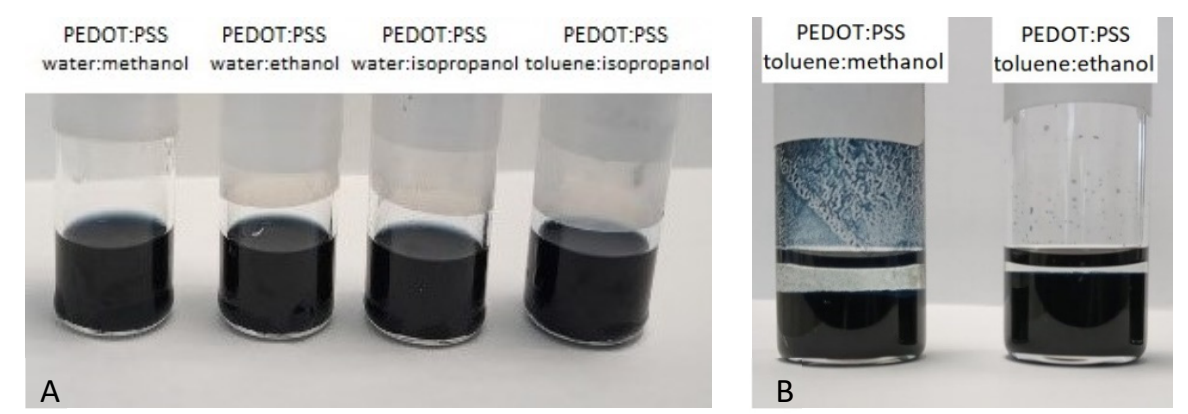

Figure 1. Poly(3,4-ethylenedioxythiophene:poly(styrenesulfonate) (PEDOT:PSS) in water or toluene mixed with different alcohols: methanol, ethanol, and isopropanol ((A) - stable mixtures, (B)-unstable mixtures).

\subsection{Preparation of PEDOT:PSS Films}

PEDOT:PSS films were prepared by spin coating, doctor blade coating, and spray coating techniques. All substrates (glass, glass/FTO, glass/ITO) were cleaned alternately with isopropanol and 
acetone, three times, prior to use. Additionally, all substrates were placed in UV Ozone Cleaner for $10 \mathrm{~min}$. The layers for each mixtures were prepared with the same set of parameters as for pristine PEDOT:PSS solutions. Films deposited by spin coater were prepared at $3000 \mathrm{rpm}$ for $90 \mathrm{~s}$. Layers made using the doctor blade device were applied at a speed of $50 \mathrm{~mm} / \mathrm{s}$, and the casting knife was set at $10 \mu \mathrm{m}$. In the case of samples prepared by spray coater, the solution was sprayed on the substrate from a height of $10 \mathrm{~cm}$ with air pressure of 2 bar. All prepared films were annealed on a hot plate at $30{ }^{\circ} \mathrm{C}$ for $20 \mathrm{~min}$.

\subsection{Methods}

A contact angle goniometer (Ossila, UK) coupled with a computer system served as the basic diagnostic tool that enabled contact angle measurements via drop shape analysis after wetting the surface with aqueous or toluene solutions. The drop images were recorded up to $5 \mathrm{~s}$ counting from the moment the drop touched the surface. The volume of a drop dosed with a syringe was on the order of $7 \mu \mathrm{L}$. As the contact angle, we used the angle between the tangent to the surface of the drop placed on the solid at the point of contact of three phases: solid, liquid, and gas.

The transmission UV-Vis spectra were acquired using an A360 UV-Vis spectrophotometer (AOR Instruments, Shanghai, China) with an interval of $0.2 \mathrm{~nm}$ and medium scan speed.

Electrochemical measurements were carried out as described in our previous work [36], using a Metrohm Autolab PGSTAT M204 potentiostat (Barendrecht, Nederland) and an electrochemical cell containing a glassy carbon electrode (diameter $2 \mathrm{~mm}$ ), a platinum rod, and $\mathrm{Ag} / \mathrm{AgCl}$ as working, counter, and reference electrodes, respectively. Potentials are referenced with respect to ferrocene $(\mathrm{Fc})$, which was used as the internal standard. Cyclic voltammetry experiments were conducted in a standard one-compartment cell, in acetonitrile (Honeywell, Charlotte, N.C., USA, $\geq 99.9 \%$ ), under argon atmosphere. Furthermore, $0.2 \mathrm{M} \mathrm{Bu}_{4} \mathrm{NPF}_{6}$ (Alfa Aesar, Haverhill, MA, USA, 99\%) was used as the supporting electrolyte. The concentration of compounds was equal to $1.0 \times 10^{-6} \mathrm{~mol} / \mathrm{dm}^{3}$. The deaeration of the solution was achieved by argon bubbling through the solution for about $15 \mathrm{~min}$ prior to the measurement. All electrochemical experiments were carried out at ambient temperature and pressure.

Thermal behavior was observed according to our standard protocol described elsewhere [17], using a thermographic camera (VIGOcam v50, VIGO System S.A, Ożarów Mazowiecki, Poland) while applying a bias voltage between 0 and $10 \mathrm{~V}$ and using a multichannel potentiostat-galvanostat (PGStat Autolab M101, Metrohm, Barendrecht, Nederland) connected to a computer. The experiment was designed to apply voltage in a programmed way. The potential was applied in a range from $0 \mathrm{~V}$ to $10 \mathrm{~V}$ with $0.5-\mathrm{V}$ steps between different values over $3 \mathrm{~min}$ for each voltage. The current response was recorded during 3-min intervals, and each step was separated with a 10-s window; when the IR image was collected, the value of the applied potential of the current step was maintained. Both the camera and the power source were controlled via computer software.

\section{Results and Discussion}

In this study, we investigated in detail a technical approach in the preparation of PEDOT:PSS layers for organic devices and their influence on optical and electrochemical properties. Our main focus was on the comparison of different PEDOT:PSS solutions based on pure solvents like water or toluene and their mixtures with three different alcohols. We performed an assessment of the wettability of different surfaces with selected solutions and their impact on the preparation of thin layers via spin coating, spray coating, or doctor blade techniques. Moreover, an evaluation of the electrochemical behavior of PEDOT:PSS in solution or in a layer was also performed.

\subsection{Contact Angle Measurements}

One of the most crucial factors to be taken into account when spreading a solution is the wettability of solid substrates. The contact angle is one of the commonly used methods to assess the wettability of 
a surface or material. Obtained results give a direct answer of whether a liquid applied over a solid surface has the tendency to exhibit good wetting properties. Usually, in this case, the contact angle is smaller than $90^{\circ}$. In the opposite situation, for non-wetting liquids, the contact angle is between 90 and $180^{\circ}$ [37]. In this study, we evaluated water- and toluene-based PEDOT:PSS solutions and the influence of the addition of alcohols such as methanol, ethanol, and isopropanol on the wetting properties of glass, glass/ITO, and glass/FTO surfaces. We focused only on the wettability aspect, which could be investigated in a simple way, giving a general comparison viewpoint for different layer preparation techniques.

\subsubsection{PEDOT:PSS in Water without and with Alcohols}

The results of static contact angle measurements for aqueous PEDOT:PSS solutions with and without the addition of alcohols are summarized in Table 1. All used solutions demonstrated good wetting properties with angles below $30^{\circ}$ for all used surfaces, as expected. The static contact angles for glass and ITO-coated glass surfaces ranged around $24-26^{\circ}$ and $19-23^{\circ}$, respectively, within the experimental error for all solutions, except for the mixture with isopropanol. The difference in the behavior, namely, the increase in hydrophobic nature, giving values reaching $30^{\circ}$, can be a result of the lower polarity of water:isopropanol with respect to pure aqueous solution and other alcohols used in this study. In the case of FTO-coated glass, the contact angle increased in the order water:methanol $\leq$ water $<$ water:ethanol $<$ water:isopropanol, giving values of $19.7^{\circ}, 22.6^{\circ}, 24.0^{\circ}$, and $25.3^{\circ}$, respectively. For this substrate, the solution with the addition of methanol gave the lowest average contact angle from the series. However, taking into account the value deviation, the value was very similar to the pure aqueous solution.

Table 1. Contact angle results for three different surfaces (glass, glass/indium tin oxide (ITO) and glass/fluorine-doped tin oxide (FTO)) for aqueous-based PEDOT:PSS solutions with and without alcohol.

\begin{tabular}{|c|c|c|c|}
\hline Sample & Substrate & Average Contact Angle $\left(^{\circ}\right)$ & Image \\
\hline \multirow{3}{*}{ PEDOT:PSS (water) } & Glass & $24.2 \pm 0.9$ & \\
\hline & ITO & $19.2 \pm 2.5$ & \\
\hline & FTO & $22.6 \pm 1.2$ & \\
\hline \multirow{3}{*}{$\begin{array}{c}\text { PEDOT:PSS } \\
\text { (water:methanol) }\end{array}$} & Glass & $26.9 \pm 2.1$ & \\
\hline & ITO & $23.2 \pm 3.3$ & \\
\hline & FTO & $19.7 \pm 0.9$ & \\
\hline \multirow{3}{*}{$\begin{array}{c}\text { PEDOT:PSS } \\
\text { (water:ethanol) }\end{array}$} & Glass & $26.2 \pm 2.5$ & \\
\hline & ITO & $22.8 \pm 1.2$ & \\
\hline & FTO & $24.0 \pm 0.8$ & \\
\hline
\end{tabular}


Table 1. Cont.

\begin{tabular}{cccc}
\hline Sample & Substrate & Average Contact Angle $\left(^{\circ}\right)$ & Image \\
\hline $\begin{array}{c}\text { PEDOT:PSS } \\
\text { (water:isopropanol) }\end{array}$ & Glass & $30.9 \pm 2.5$ \\
& ITO & $28.7 \pm 3.5$ & \\
& FTO & $25.3 \pm 1.6$ & \\
\hline
\end{tabular}

\subsubsection{PEDOT:PSS in Toluene without and with Alcohols}

A similar experiment was also performed for toluene-based PEDOT:PSS solutions with and without the addition of alcohol. In these cases, the solutions demonstrated good wetting properties with angles below $30^{\circ}$ for all used surfaces, as expected. It was noticed that solutions containing methanol and ethanol formed emulsions and suffered from low stability, resulting in separation over time. The separation was relatively fast and occurred in the syringe used for contact angle measurements; therefore, contact angle measurements for PEDOT:PSS in toluene:methanol and toluene:ethanol were not recorded. The results of wettability are presented in Table 2. The toluene-based solution with and without isopropanol displayed very similar behavior, resulting in the surfaces having decreasing wettability in the order ITO-coated glass < glass $<$ FTO-coated glass.

Table 2. Contact angle results for three different surfaces (glass, glass/ITO, and glass/FTO) for toluene-based PEDOT:PSS solutions with and without alcohol.

\begin{tabular}{cccc}
\hline Sample & Substrate & Average Contact Angle $\left(^{\circ}\right.$ ) & Image \\
\hline PEDOT:PSS (toluene) & Glass & $20.2 \pm 0.9$ \\
& ITO & $18.3 \pm 4.2$ & \\
\hline $\begin{array}{c}\text { (PEDOT:PSS } \\
\text { toluene:isopropanol) }\end{array}$ & GTO & $20.2 \pm 2.0$ \\
\hline
\end{tabular}

\subsection{PEDOT:PSS Layer Preparation Via Three Different Techniques}

In this section, PEDOT:PSS layers were prepared via three techniques, namely, spin coating, doctor blade, and spray coating. The application parameters for individual devices were selected during the initial optimization process. The focus of this section was on the evaluation of three different film-forming techniques in order to select the best one that gives reproducible results using PEDOT:PSS water- or toluene-based solutions with or without the addition of alcohol. 


\subsubsection{Spin Coating}

As the first step of this work, selected parameters were changed to optimize the spin coating technique. We changed the speed value from 2000 to $4000 \mathrm{rpm}$ and time from 30 to $90 \mathrm{~s}$ until we found the best technical parameters for the PEDOT:PSS solutions (Figure 2A). Details of the optimization of the spin coating technique for PEDOT:PSS in water and toluene are presented in Supplementary Materials (Figures S1 and S2).
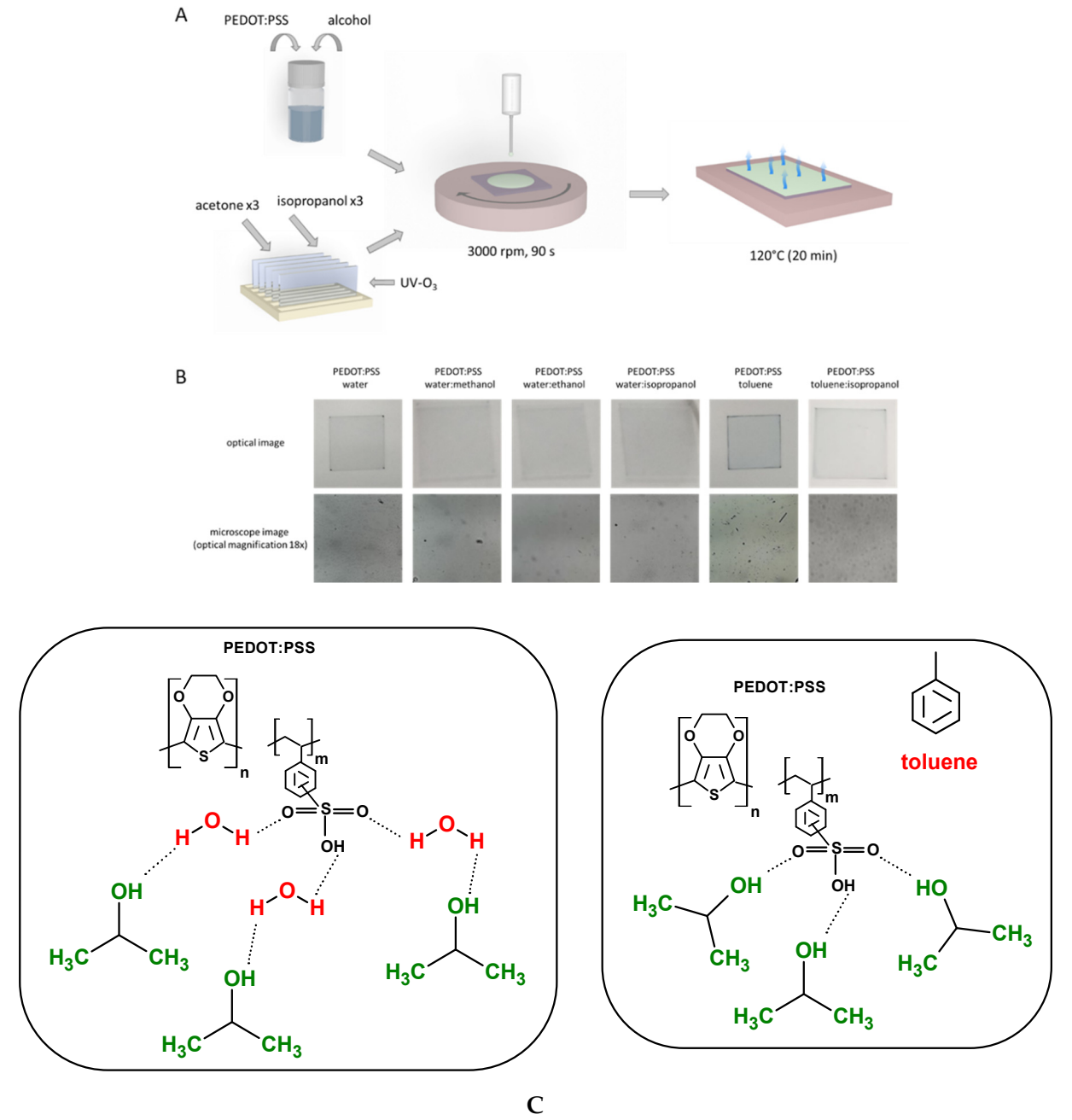

Figure 2. Scheme of layer preparation using spin coating technique (A); images of PEDOT:PSS layers (spin coated at $3000 \mathrm{rpm}, 90 \mathrm{~s}$ ) and microscopic images acquired at optical magnification of 18× (B); scheme of primary and secondary hydrogen bond interactions of PEDOT:PSS in water and toluene with isopropanol (C).

In our case, for the spin coater, the optimal speed value was found to be $3000 \mathrm{rpm}$ for $90 \mathrm{~s}$. The layer obtained in such conditions was estimated to have $80 \mathrm{~nm}$ thickness, based on the spin speed to thickness correlation provided by Ossila. Due to the specific limitations of this technique, it was possible to obtain repeatable samples for both water- and toluene-based solutions. Layers of PEDOT:PSS with and without alcohols obtained via spin coating were more homogeneous (see Figure 2B). In Figure 2B (lower row), the microscopic images show in more detail the reduction in the presence of small spots for samples prepared from the pure solution and with the addition of alcohol. There was no difference between pure solutions or between different alcohols present in the mixture. Based on our understanding, the improvement in layer formation due to the presence of isopropyl alcohol can be related to the improved interaction between polymer and solvent. The advantage of 
isopropanol over other tested alcohols is related to its chemical structure and the longer hydrocarbon chain, as schematically presented in Figure 2C. In the case of the water solution of PEDOT:PSS, primary hydrogen bond interactions existed between the hydrogen atom of water and the oxygen atoms in $\mathrm{SO}_{3} \mathrm{H}$ groups of the PSS polymer. Moreover, $\mathrm{H}-\mathrm{H}$ interactions cannot be excluded. In the case of the toluene solution of PEDOT:PSS, these reactions did not take place. In both solutions of PEDOT:PSS, interactions between the alcohol and $\mathrm{OH}$ or $\mathrm{SO}_{3} \mathrm{H}$ groups are possible, as schematically presented in Figure 2C. It should be stressed that, in the case of PEDOT:PSS in the water solution, alcohol was used as a secondary dopant because water was the first one. In the case of the toluene solution of PEDOT:PSS, alcohol was the primary dopant. Moreover, it should be stressed that the most spectacular changes in morphology of created layers were found for layers with isopropanol as a dopant, probably because of the symmetry of this alcohol and steric hinderance.

\subsubsection{Doctor Blade Technique}

Selected parameters were also changed to optimized the process of layer formation for the doctor blade technique. We changed the gap value as 10,25 , and $50 \mu \mathrm{m}$ and speed rate as 20,50 , and $80 \mathrm{~mm} / \mathrm{s}$ to find the best technical parameters for PEDOT:PSS solutions. Details of the optimization of the doctor blade technique for PEDOT:PSS in water and toluene are presented in Supplementary Materials (Figures S3 and S4).

PEDOT:PSS layers were applied with a doctor blade device with a gap set at the 10- $\mu \mathrm{m}$ layer with $50 \mathrm{~mm} / \mathrm{s}$ film developing speed (Figure 3A). Formation of layers using this technique was quite problematic. The problematic part was the aqueous or toluene solution's tension while spreading the solution on the surface. Moreover, in the case of the aqueous layer applied on the surface after annealing, crack formation resulted over the whole layer (Figure 3B,C, middle image). The addition of alcohol was beneficial for a reduction in surface tension, and the formed layer did not crack; however, the homogeneity aspect was not met.

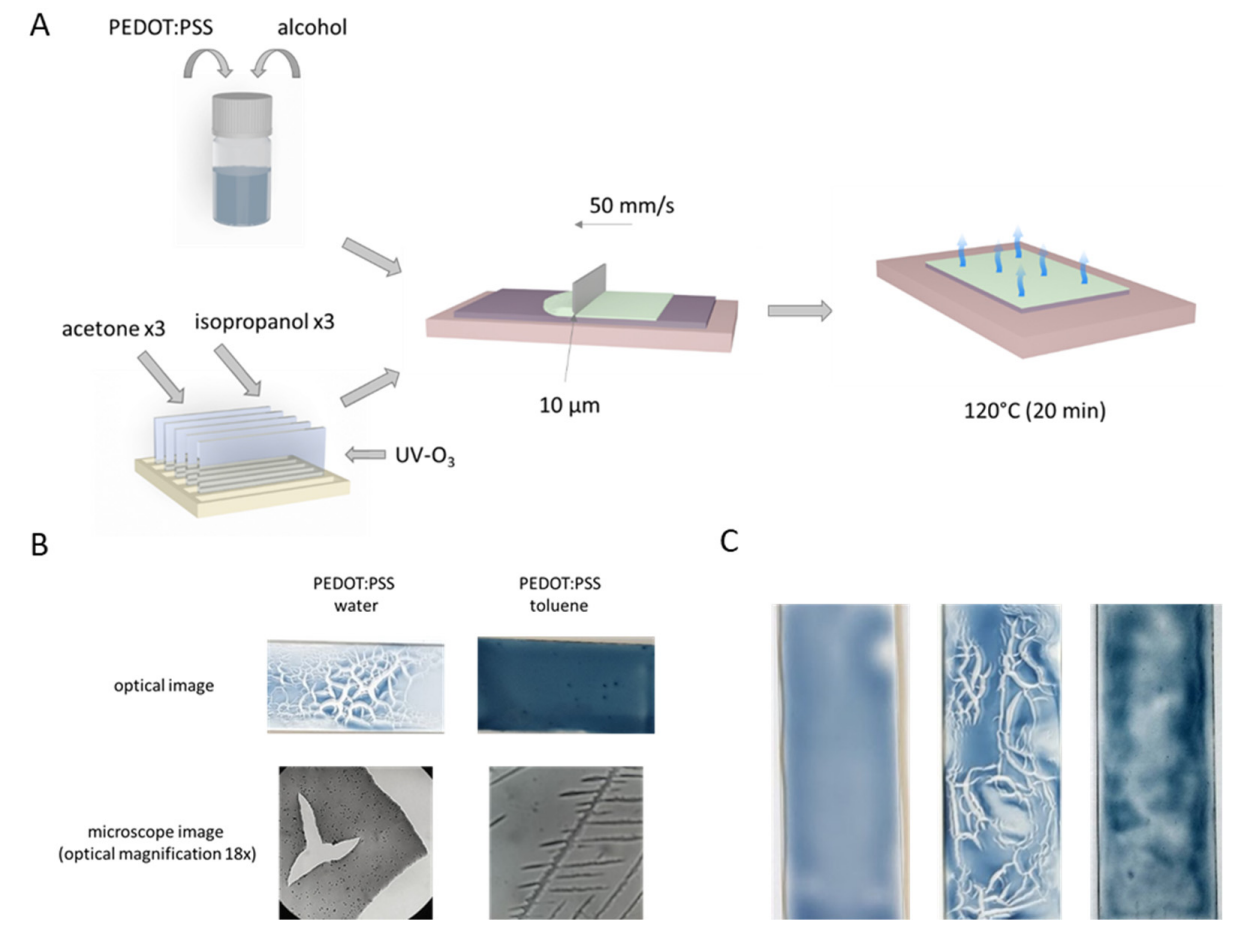

Figure 3. Scheme of layer preparation using doctor blade technique (A); images of PEDOT:PSS layers (10 $\mu \mathrm{m}$ gap, $50 \mathrm{~mm} / \mathrm{s})$ and microscopic images acquired at optical magnification of $18 \times(\mathbf{B})$; PEDOT:PSS (from water) layer (from left to right): directly after casting, after annealing, and layer made from PEDOT:PSS (from water:isopropanol) layer after annealing $(\mathbf{C})$. 
In the case of toluene-based solutions after annealing, a visually more homogenous layer was formed (see Figure 3B, top right). The PEDOT:PSS layer under 18 $\times$ magnification revealed the formation of long crystalline patterns present in layers formed in the mixtures with alcohols (Figure 3B, bottom right). It seems that a thick layer was formed due to the liquid surface tension, which would be unacceptable for fine organic devices.

\subsubsection{Spray Coating}

In the case of spray coating, we changed the distance between spray and substrate from 6 to $14 \mathrm{~cm}$ to create the best PEDOT:PSS layers. Details of the optimization of the spray coating technique for PEDOT:PSS in water and toluene are presented in Supplementary Materials (Figures S5 and S6).

The last technique used was a spray coating set-up composed of an airbrush connected to a Metabo Basic 250-24W compressor. The layers were sprayed from a height of $10 \mathrm{~cm}$ at an air pressure of $2 \mathrm{bar}$ (Figure 4A). This technique had a similar problem to the doctor blade technique regarding the tension of used solvents. The principle of this technique is the formation of droplets, and their accumulation forms the final layer. Spraying aqueous-based solutions resulted in the formation of uneven layers due to the cone-shaped stream, where the center was more likely to receive more solution. This technical issue can easily be avoided by using a more precise device for solution application. However, the PEDOT:PSS layers from water, water:methanol, and water:ethanol where inhomogeneous, whereas layers made from water:isopropanol (Figure $4 \mathrm{~B}$, top row) showed the formation of relatively homogenous layers, as confirmed by optical microscopy (Figure 4 B, bottom row).

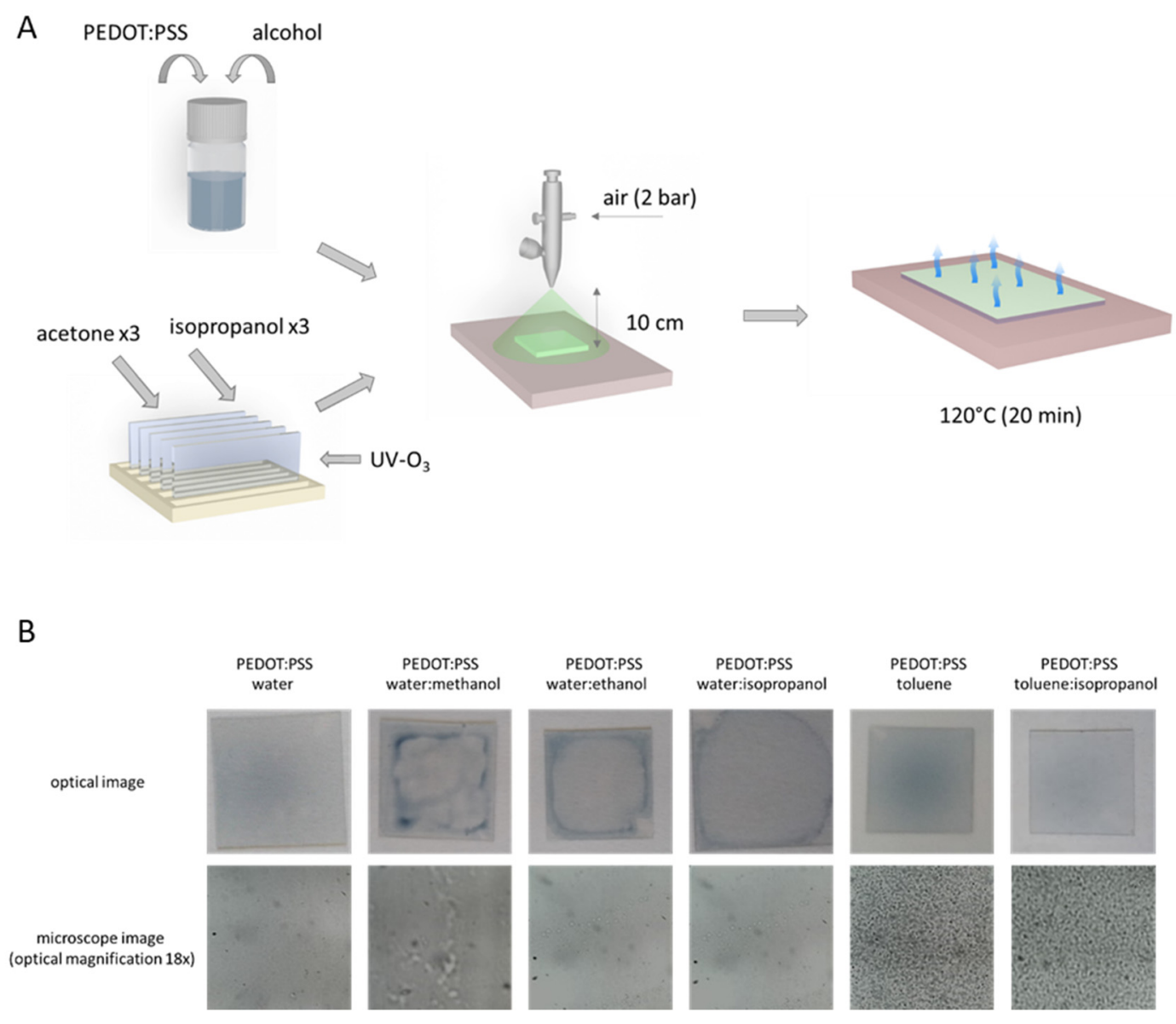

Figure 4. Scheme of layer preparation using spray coating technique (A); images of PEDOT:PSS layers (spray coated, $10 \mathrm{~cm}$ distance, pressure $2 \mathrm{bar}$ ) and microscopic images acquired at optical magnification of $18 \times(B)$. 
The layers prepared from toluene-based PEDOT:PSS both with and without isopropanol addition gave better layers in terms of visual quality compared to aqueous solutions. The biggest disadvantage was the formation of small agglomerates observed under the optical microscope (magnification 18x), which would hinder the application of these samples. The agglomerate formation is related to the mechanism of layer formation using this technique; during dispersion of the polymeric solution, before the solution gets into contact with the solid surface, it loses solvent via partial evaporation. Due to this fact, in some parts of the formed layer, there were small droplets containing undissolved polymeric material [38]. This effect was observed in the case of toluene-based solutions due to its better volatilization (Figure 4B).

\subsection{Electrochemical Study}

In order to study electrochemical properties of different PEDOT:PSS solutions, cyclic voltammetry (CV) was employed. The first step was to record voltammetry curves for solutions and solvent to identify characteristic signals for single components. The second step involved the electrochemical study of layers on FTO-coated glass, while the third step elucidated the aging process and its influences on the electrochemical response.

\subsubsection{CV of PEDOT:PSS in Water and Toluene without and with Alcohols}

The first step involved aqueous and toluene-based PEDOT:PSS solutions, as well as their mixtures with methanol, ethanol, and isopropanol and pure solvents. The cyclic voltammetry response was very stable in the measured range from -2.37 to $0.70 \mathrm{~V}$ (see Table 3). In all cases, the response was almost fully reversable, which means that degradation processes were not observed (see Figure 5). The electrochemical response to oxidation conditions for the PEDOT molecule involved acceptance of an electron, which caused rearrangement of the conjugation of double bonds and the formation of a cation and unpaired electron. The second step of oxidation resulted in complete oxidation where only cations are present [39]. It seems that, in the case of water-based solutions, the oxidation to the fully oxidized step occurred in one step, with oxidation onset at $0.38 \mathrm{~V}$. Similar oxidation behavior was observed for the toluene-based PEDOT:PSS solution with oxidation onset at $1.22 \mathrm{~V}$. On the other hand, the reduction of both starting solutions also differed, giving values of offset points at $-1.14 \mathrm{~V}$ and $-1.83 \mathrm{~V}$ for PEDOT:PSS in water and toluene, respectively. The difference in redox energies for both solutions was significant in terms of the energy gap $\left(E_{g}\right)$, and, in this case, the gap was smaller for the toluene-based solution than for the water-based solution by about $0.19 \mathrm{eV}$. The addition of alcohol to PEDOT:PSS in water resulted in an extension of over $1 \mathrm{eV}$ compared to the starting solution. The best result from the electrochemical point of view was achieved for the water:isopropanol mixture giving an $\mathrm{E}_{\mathrm{g}}$ value equal to $2.85 \mathrm{eV}$. The electrochemical series in terms of solvent-containing water based on decreasing $E_{g}$ value was water:isopropanol > water:methanol > water:ethanol > water.

Table 3. Summary of selected electrochemical values and dipole moments for aqueous and toluene-based solutions of PEDOT:PSS with and without of alcohol.

\begin{tabular}{ccccc}
\hline Sample (Solutions) & $\mathbf{E}_{\text {HOMO, }} \mathbf{e V}$ & $\mathbf{E}_{\text {LUMO }} \mathbf{e V}$ & $\begin{array}{c}\text { Energy Bandgap } \\
(\mathbf{e V})\end{array}$ & $\begin{array}{c}\text { Dipole Moments } \\
\text { of Dopants (D) }\end{array}$ \\
\hline PEDOT:PSS (water) & -4.84 & -3.45 & 1.39 & 1.85 \\
PEDOT:PSS (water:methanol) & -5.09 & -2.75 & 2.34 & $1.85: 1.70$ \\
PEDOT:PSS (water:ethanol) & -5.03 & -2.74 & 2.29 & $1.85: 1.69$ \\
PEDOT:PSS (water:isopropanol) & -5.05 & -2.20 & 2.85 & $1.85: 1.66$ \\
PEDOT:PSS (toluene) & -4.81 & -3.61 & 1.20 & 0.39 \\
PEDOT:PSS (toluene:methanol) & -5.32 & -3.26 & 2.06 & $0.39: 1.70$ \\
PEDOT:PSS (toluene:ethanol) & -5.64 & -3.60 & 2.04 & $0.39: 1.69$ \\
PEDOT:PSS (toluene:isopropanol) & -6.15 & -3.61 & 2.54 & $0.39: 1.66$ \\
\hline
\end{tabular}



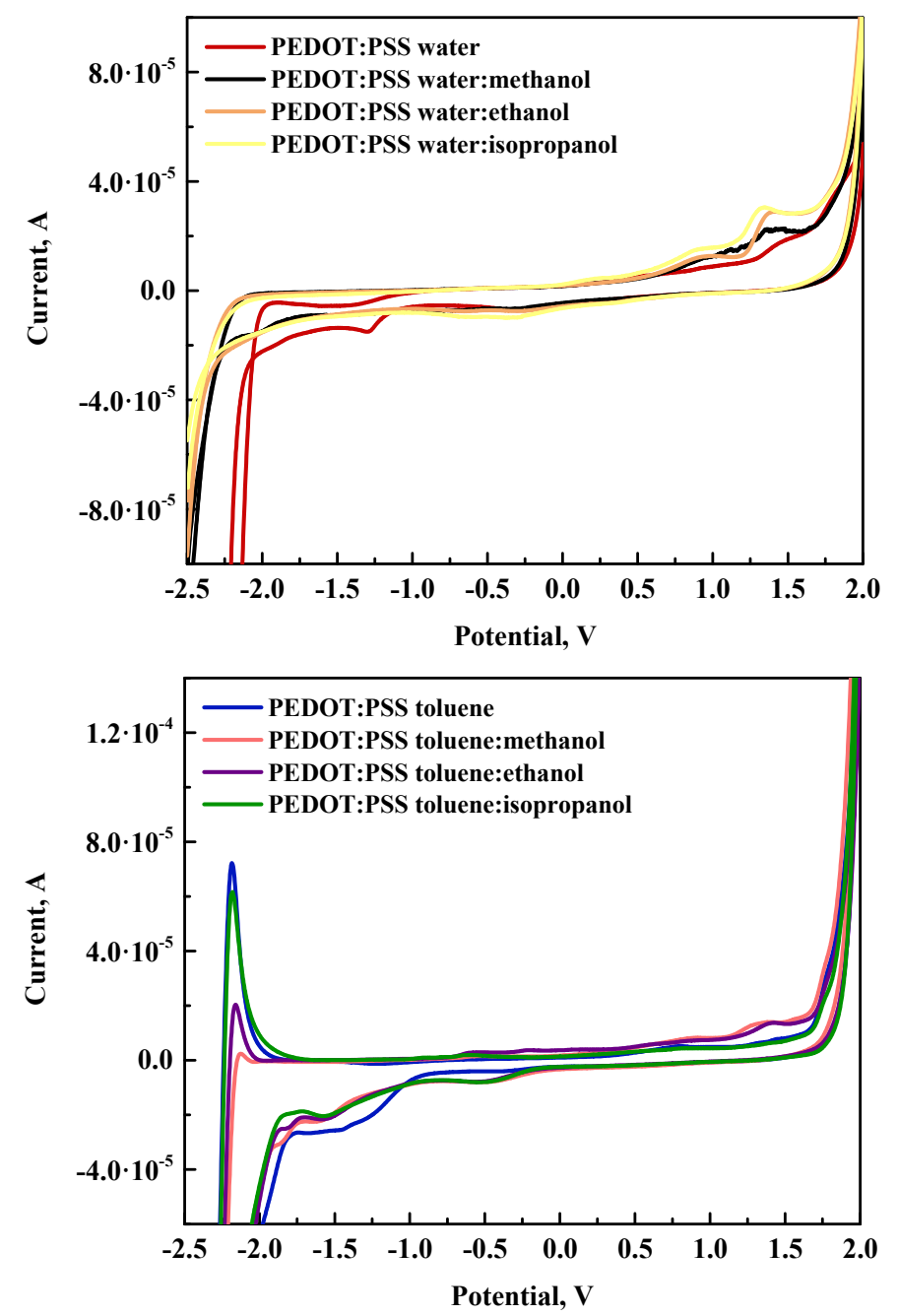

Figure 5. Comparative cyclic voltammetry (CV) curves for PEDOT:PSS in water (top) and toluene (bottom).

In the case of PEDOT:PSS in toluene, the addition of alcohol also expanded the electrochemical window, giving the highest value for the toluene:isopropanol mixture at $2.54 \mathrm{eV}$. The results for the mixture with methanol and ethanol gave similar nominal $\mathrm{E}_{\mathrm{g}}$; however, the values shifted by approximately $0.30 \mathrm{eV}$ toward more negative potentials.

For all samples, additional oxidation maxima at approximately $1.5 \mathrm{~V}$ were observed, which can be a consequence of reversible oxidation of some $-\mathrm{OH}$ alcohol groups at the platinum electrode [40]. This was also noted in reference measurements performed for pure alcohols.

We based our investigation on commercially available homogenous solutions of PEDOT:PSS in water or in toluene. As a dopant, we used methanol, ethanol, or isopropanol with various dipole moments, as presented in Table 3. It is known that compounds with similar solubility parameters are able to interact with each other, resulting in solvation, miscibility, or swelling. We could conclude that, taking into consideration the dipole moments of the applied alcohols, better solubility should be seen for the water solution of PEDOT:PSS based on the similar values of dipole moments for primary and secondary hydrogen bond interactions.

\subsubsection{CV of PEDOT:PSS Layers on Glass/FTO Substrate}

In the second step, layers based on PEDOT:PSS solutions in different solvents were prepared via the spin coating method over FTO-coated glass substrate due to the better quality of redox signals registered in the CV curve compared to samples prepared on ITO. In this evaluation, toluene:methanol 
and toluene:ethanol were not examined due to the instability of solutions. The experimental values of HOMO, LUMO, and energy bandgap are shown in Table 4.

Table 4. Summary of selected electrochemical values for layers prepared from aqueous and toluene based solutions of PEDOT:PSS with and without of alcohol.

\begin{tabular}{cccc}
\hline Sample (Layers) & E $_{\text {HOMO }}(\mathbf{e V})$ & E $_{\text {LUMO }}(\mathbf{e V})$ & Energy Bandgap (eV) \\
\hline PEDOT:PSS from water & -5.05 & -3.46 & 1.59 \\
PEDOT:PSS from water:methanol & -4.98 & -3.65 & 1.33 \\
PEDOT:PSS from water:ethanol & -4.93 & -3.65 & 1.28 \\
PEDOT:PSS from water:isopropanol & -4.97 & -3.60 & 1.37 \\
PEDOT:PSS from toluene & -4.93 & -3.41 & 1.52 \\
PEDOT:PSS from toluene:isopropanol & -5.06 & -3.44 & 1.62 \\
\hline
\end{tabular}

Generally, upon comparing obtained results for all created layers, it can be easy noted that the HOMO-LUMO limit values were very similar to each other unlike the electrochemical response in solution. This might be an effect of concentration. In solution, the PEDOT:PSS was diluted, whereas, in the form of a thin layer, it was more concentrated. The series of PEDOT:PSS layers depending on used solvent can be organized in terms of decreasing $E_{g}$ value as follows: toluene:isopropanol $>$ water $>$ toluene $>$ water:isopropanol $>$ water:methanol $>$ water:ethanol. The values of energy gap for starting solutions were very similar to those obtained for solutions, where the aqueous solution had a higher value. In the case of layers, the signals for the presence of alcohol in the structure were not observed. In Figure 6, a comparison of all CV curves for PEDOT:PSS layers can be observed. The most visible difference in the spectra was the oxidation signal, which changed depending on the used solution for layer preparation. This might suggest that traces of solvent were present in the formed layer even after annealing at $130{ }^{\circ} \mathrm{C}$. Additionally, the presence of alcohol had a significant impact on the oxidation process occurring in the layer. for the toluene-based solution, isopropanol caused a shift toward positive potentials, increasing the energy bandgap. The opposite situation took place for the water-based solution, where the addition of alcohol caused a shift in oxidation band toward lower potentials, resulting in decreases in $\mathrm{Eg}_{\mathrm{g}}$ by $0.22 \mathrm{eV}, 0.26 \mathrm{eV}$, and $0.31 \mathrm{eV}$ for isopropanol, methanol, and ethanol, respectively.

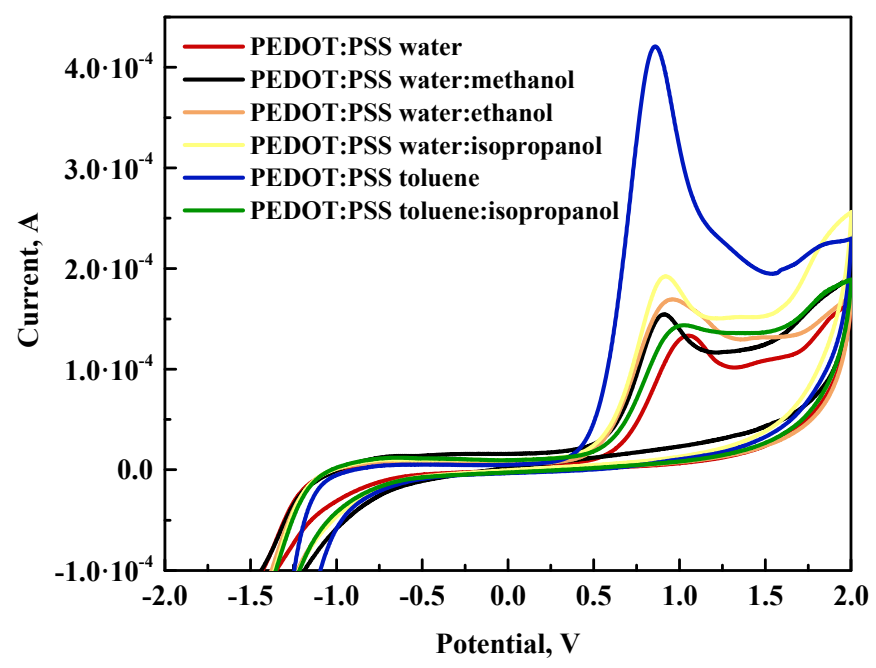

Figure 6. Comparative summary of CV curves for all tested PEDOT:PSS layers.

\subsubsection{PEDOT:PSS in Water without and with Alcohols in Layers: Storage Effect}

In order to evaluate the stability of prepared PEDOT:PSS layers, we carried out short-term storage up to three days in a dark box and argon atmosphere. After each day, the electrochemical performance 
of the new sample was tested in order to detect any changes in the CV curve. The storage in the abovementioned conditions affected only the LUMO level, thereby causing changes in the energy bandgap (Table 5). It was not possible to find any specific trend for the set of samples. Based on our understanding, the results presented a response to various phenomena such as the evaporation of enclosed solvent or water adsorption from humid air. In our opinion, in order to preserve the original properties of the layer, the best way is to always use a freshly prepared sample.

Table 5. The results of energy bandgap values for layers after different storage periods.

\begin{tabular}{ccccc}
\hline Sample (Layers) & Day 0 & Day 1 & Day 2 & Day 3 \\
\cline { 2 - 5 } & \multicolumn{5}{c}{ Energy Bandgap (eV) } \\
\hline PEDOT:PSS from water & 1.59 & 1.38 & 1.43 & 1.77 \\
PEDOT:PSS from water:methanol & 1.33 & 1.54 & 1.48 & 1.72 \\
PEDOT:PSS from water:ethanol & 1.28 & 1.42 & 1.48 & 1.41 \\
PEDOT:PSS from water:isopropanol & 1.37 & 1.53 & 1.54 & 1.57 \\
PEDOT:PSS from toluene & 1.52 & 1.57 & 1.47 & 1.46 \\
PEDOT:PSS from toluene:isopropanol & 1.62 & 1.71 & 1.67 & 1.45 \\
\hline
\end{tabular}

\subsection{UV-Vis Study}

The hole transport layer (HTL) in organic solar cells such as PEDOT:PSS should be as transparent as possible. We investigated the influence of the addition of alcohols on the transmittance of PEDOT:PSS films. The UV-Vis measurements were carried out for layers made with a spin coater ( $3000 \mathrm{rpm}, 90 \mathrm{~s})$ on a thin glass substrate to avoid the additional influence coming from the thickness of the glass or deposed conductive layers of ITO or FTO. Details on the influence of technical parameters of spin coating on the transmittance spectra are presented in Supplementary Materials (Figures S7 and S8).

Figure 7 shows the transmittance spectra for all tested PEDOT:PSS films. At wavelengths larger than $350 \mathrm{~nm}$, the transparency of all films remained at a level of $85 \%$, while they remained at a level of $80 \%$ up to $850 \mathrm{~nm}$. On the other hand, for PEDOT:PSS (toluene) films, the value of transmittance dropped slightly to $80 \%$. This means that the addition of alcohols to PEDOT:PSS solutions practically did not affect the transparency of formed layers.

As shown in Figure 7, the type of solvent and dopant influenced changes in the transmittance of the investigated layers. Transmittance for the PEDOT:PSS toluene film mainly dropped in the absorption range from 550 to $850 \mathrm{~nm}$. As explained previously for the water solution, taking into consideration primary and secondary H-bonding, a small drop in transmittance was found due to the dipole moment of alcohol used (a small drop was observed for isopropanol and ethanol used as dopant compared with water and water with methanol). The highest drop was found for the toluene:isopropanol mixture compared with all investigated samples (Figure 7, bottom). 

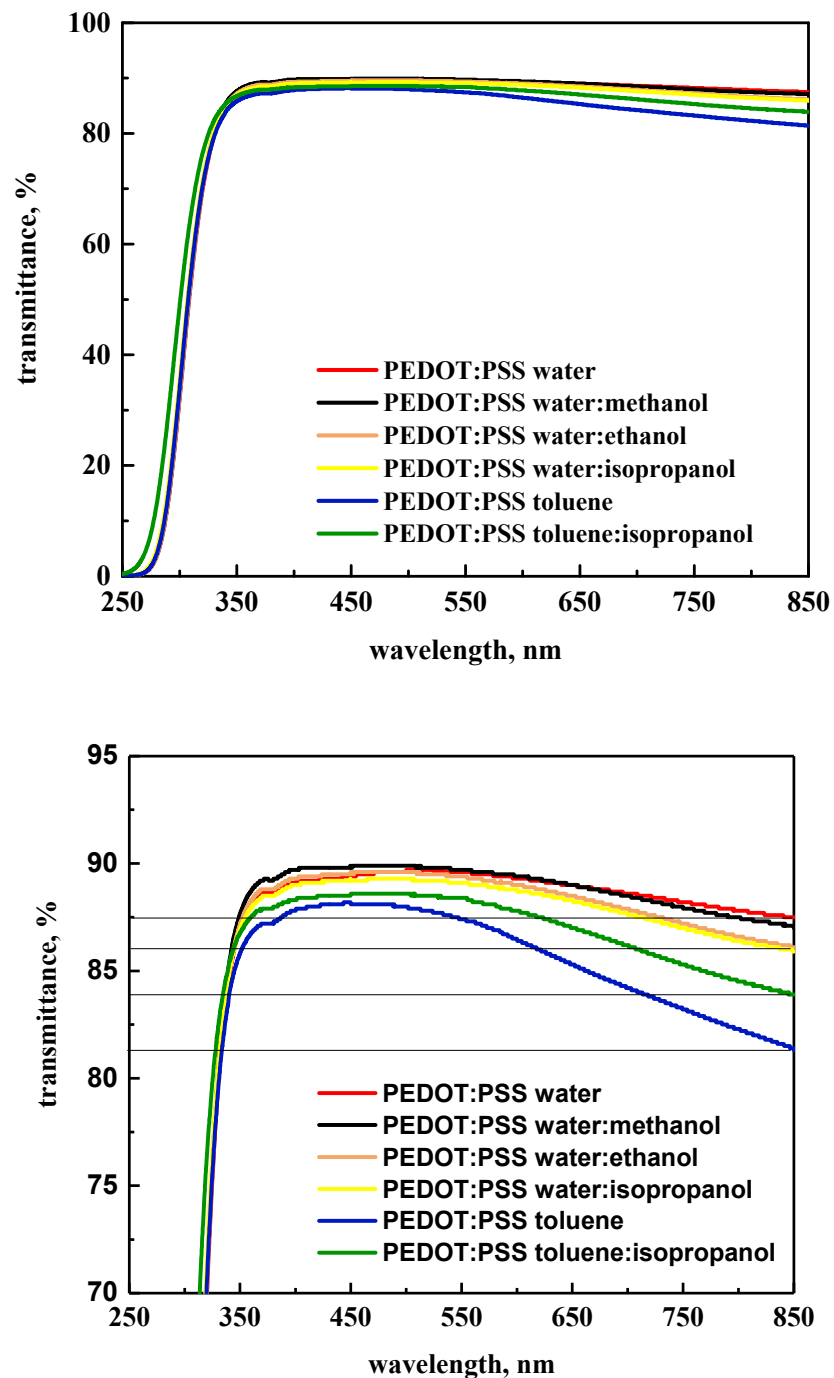

Figure 7. UV-Vis spectra of PEDOT:PSS layers in full (top) and from 70\% to 95\% (bottom) transition mode.

\subsection{IR Thermography Study}

For thermal imaging, four samples (PEDOT:PSS from water, water:isopropanol, toluene, and toluene:isopropanol) were selected. These four samples showed the best electrochemical behavior from the whole series. Thermal imaging was used to observe overall behavior of the sample device during application of an external potential. For this experiment, the active layers were prepared using the spin coating technique over ITO-coated glass support. The architecture of the devices was as follows:

- ITO/PEDOT:PSS(water)/Ag/ITO;

- ITO/PEDOT:PSS(water:isopropanol)/Ag/ITO;

- ITO/PEDOT:PSS(toluene)/Ag/ITO;

- ITO/PEDOT:PSS(toluene:isopropanol)/Ag/ITO.

In Figure 8, IR images are presented for all architectures at selected voltages. In general, for all devices, a very similar pattern of temperature topography was observed. As can be seen in the exemplary images, upon increasing the voltage, two main heating centers located in proximity to both metallic contacts were observed. In the images at $10 \mathrm{~V}$, it is more evident that the heating zone also included the middle part of the active area (see Figure 8, last row). This might suggest that the current flow occurred via the shortest available way. The heat concentration close to the metallic clamps 
can be explained by the concentration of the current flow close by, as well as due to the imperfect interface between metal and ITO, as observed in our previous work [17,24]. During the experiments, the maximum observed temperature ranged between $40{ }^{\circ} \mathrm{C}$ and $100{ }^{\circ} \mathrm{C}$ (see Figure 9). The highest temperatures were observed for the ITO/PEDOT:PSS(toluene)/Ag/ITO architecture, whereas the lowest observed temperature was observed for ITO/PEDOT:PSS(water:isopropanol)/Ag/ITO. For samples with the addition of isopropanol, a decrease by about $30{ }^{\circ} \mathrm{C}$ in thermal response compared to the corresponding pure solvent was noted. For ITO/PEDOT:PSS(water:isopropanol)/Ag/ITO at $10 \mathrm{~V}$, a small drop in temperature was also noted; however, this was not correlated to any topographic temperature change.

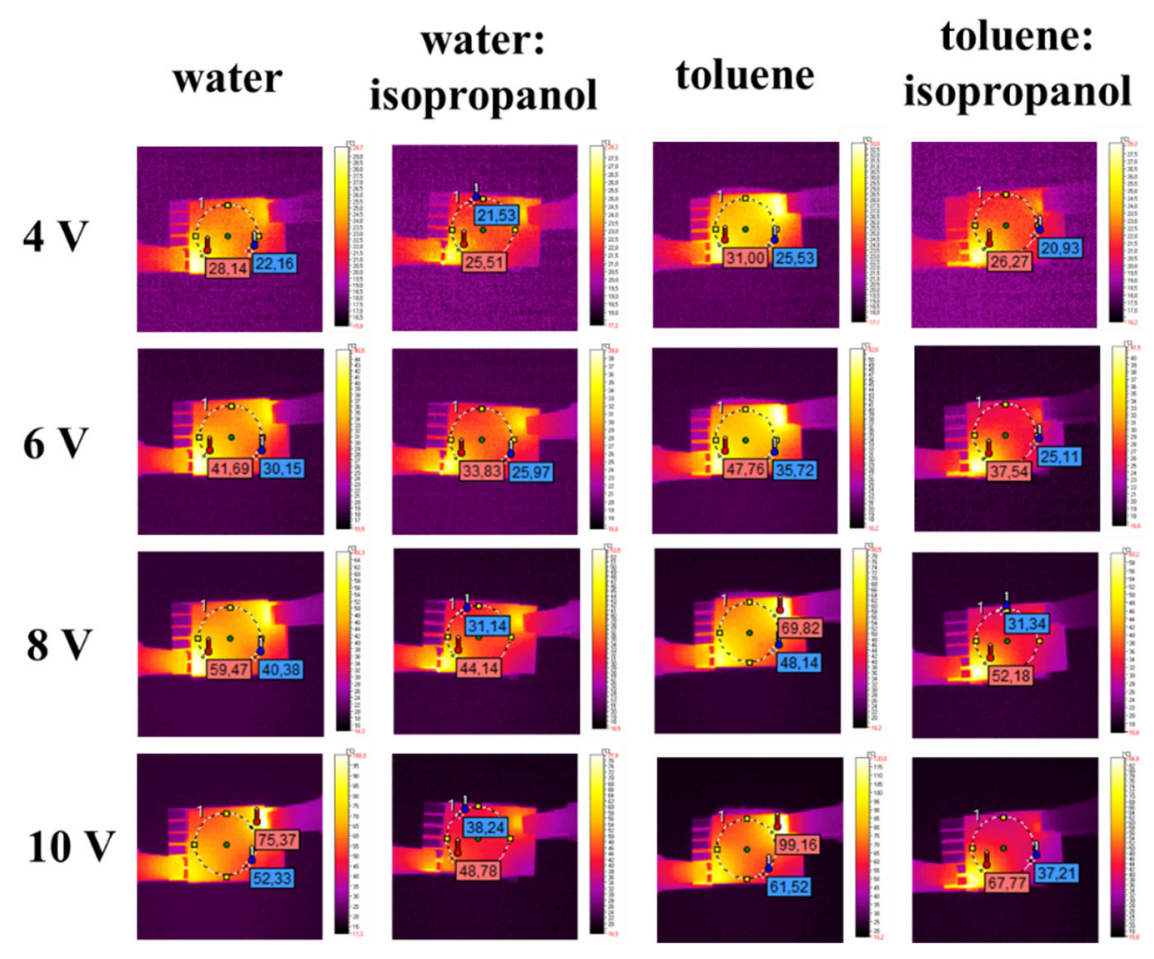

Figure 8. IR images obtained for device architectures (from left to right): ITO/PEDOT:PSS(water)/Ag/ITO, ITO/PEDOT:PSS(water:isopropanol)/Ag/ITO, ITO/PEDOT:PSS(toluene)/Ag/ITO, and ITO/PEDOT:PSS(toluene:isopropanol)/Ag/ITO at $4.0 \mathrm{~V}, 6.0 \mathrm{~V}, 8.0 \mathrm{~V}$, and $10.0 \mathrm{~V}$.

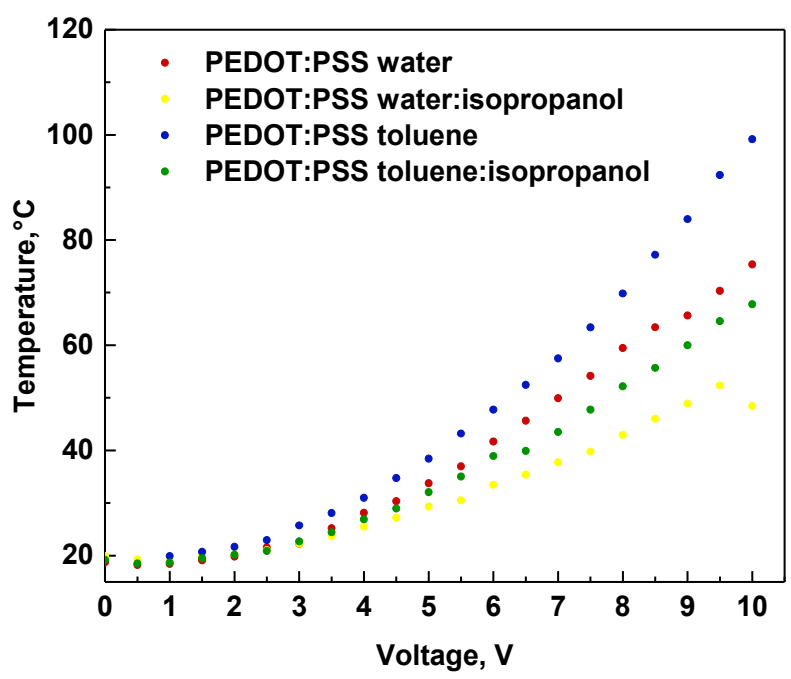

Figure 9. The correlation of temperature versus applied potential for constructed devices containing PEDOT:PSS from water, water:isopropanol, toluene, and toluene:isopropanol. 
The analysis of electrical conductivity for all tested samples revealed the behavior of electric conductors correlated with the applied voltage (Figure 10). The resistance values ranged from $45.68 \Omega$ to $121.24 \Omega$. The results are consistent with the thermal behavior for all samples except for that containing PEDOT:PSS from the toluene:isopropanol solution. In this case, the sample displayed the highest resistance among all samples; however, the temperature observed during current flow was not the highest. This might suggest that part of the electricity was converted to heat. Moreover, a small drop in current at $10 \mathrm{~V}$ for ITO/PEDOT:PSS(water:isopropanol)/Ag/ITO was also observed, which influenced the thermal response of the sample.

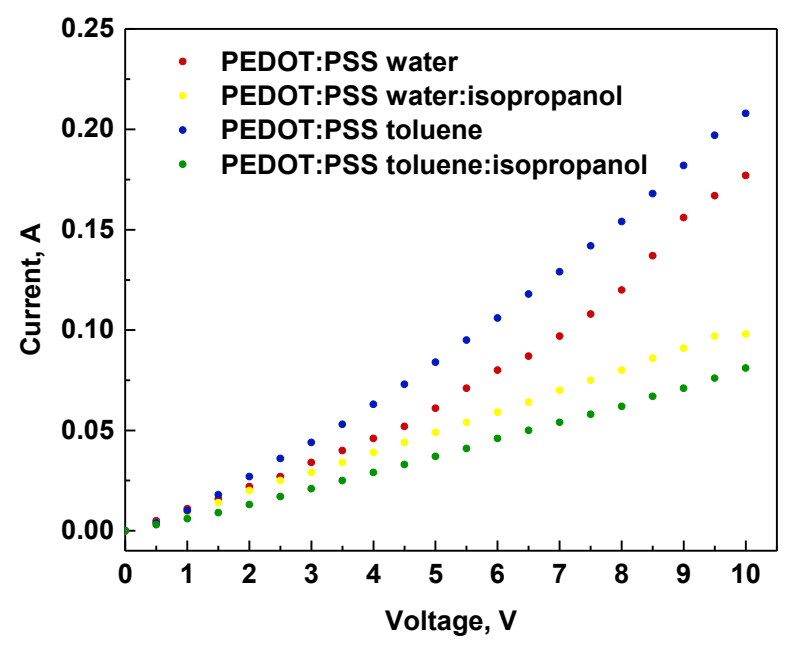

Figure 10. The correlation of current with applied potential for constructed devices containing PEDOT:PSS from water, water:isopropanol, toluene, and toluene:isopropanol.

\section{Conclusions}

To summarize, in our study we presented a technical approach for the preparation of PEDOT:PSS layers for organic devices. Our main focus was on the comparison of different PEDOT:PSS solutions based on pure solvents like water or toluene and their mixtures with three different alcohols. The results of our study demonstrated the following:

- The presence of alcohol did not have a significant influence on the wetting abilities of the prepared solutions for all three tested surfaces (glass, ITO, and FTO);

- In our study, the spin coating technique showed the best reproducibility and homogeneity of prepared samples compared to other techniques on a laboratory scale;

- The preparation of thick layers promotes the crystallization of PEDOT:PSS in the layer;

- The adjustability of $E_{g}$ of layers (mainly in terms of LUMO levels) decreased the starting value in the presence of alcohol;

- The presence of isopropanol in PEDOT:PSS solutions used for layer preparation caused an almost two-fold increase in electrical resistance, as well as a decrease in thermal response by $30^{\circ} \mathrm{C}$.

We can conclude that, for laboratory-scale or small-scale preparation of organic devices, the best technique would be spin coating, which allows the greatest precision in adjusting the parameters. Moreover, the addition of isopropanol allows changing the original behavior of PEDOT:PSS.

Supplementary Materials: The following are available online at http://www.mdpi.com/2073-4360/12/3/565/s1: Figure S1: Photos of PEDOT:PSS (from water) layer created with a speed value from 2000 to $4000 \mathrm{rpm}$ and time from 30 to $90 \mathrm{~s}$ from top to bottom, along with images detected by optical microscope with magnification $18 \times$; Figure S2: Photos of PEDOT:PSS (from toluene) layer created with a speed value from 2000 to $4000 \mathrm{rpm}$ and time from 30 to $90 \mathrm{~s}$ from top to bottom along with images detected by optical microscope with magnification 18x; Figure S3: Photos of PEDOT:PSS (from water) layer created with the gap set value at 10, 25, and $50 \mu \mathrm{m}$ and speed rate at 20,50, and $80 \mathrm{~mm} / \mathrm{s}$; Figure S4: Photos of PEDOT:PSS (from toluene) layer created with the gap set 
value at 10, 25, and $50 \mu \mathrm{m}$ and speed rate at $50 \mathrm{~mm} / \mathrm{s}$; Figure S5: Photos of PEDOT:PSS (from water) layer created by changing the distance between spray and substrate from 6 to $14 \mathrm{~cm}$; Figure S6: Photos of PEDOT:PSS (from toluene) layer created by changing the distance between spray and substrate from 6 to $14 \mathrm{~cm}$; Figure S7: UV-Vis spectra of PEDOT:PSS (from water) layers in transition mode with a speed value from 2000 to $4000 \mathrm{rpm}$ and time from 30 to $90 \mathrm{~s}$ from top to bottom; Figure S8: UV-Vis spectra of PEDOT:PSS (from toluene) layers in transition mode with a speed value from 2000 to $4000 \mathrm{rpm}$ and time from 30 to $90 \mathrm{~s}$ from top to bottom.

Author Contributions: Conceptualization, A.I.; methodology, K.A.B.; investigation, B.J., K.A.B., W.P., and I.P.; writing-original draft preparation, A.I.; writing-review and editing, K.A.B.; visualization, B.J. and W.P.; supervision, K.A.B.; funding acquisition, A.I. All authors read and agreed to the published version of the manuscript.

Funding: The authors are grateful for the financial support from the Polish National Center of Research and Development (TECHMATSTRATEG1/347431/14/NCBR/2018).

Conflicts of Interest: The authors declare no conflicts of interest.

\section{References}

1. Cao, S.; Li, B.; Zhu, R.; Pang, H. Design and synthesis of covalent organic frameworks towards energy and environment fields. Chem. Eng. J. 2019, 355, 602-623. [CrossRef]

2. Facchetti, A. Organic semiconductors: Made to order. Nat. Mater. 2013, 12, 598-600. [CrossRef] [PubMed]

3. La Notte, L.; Cataldi, P.; Ceseracciu, L.; Bayer, I.S.; Athanassiou, A.; Marras, S.; Villari, E.; Brunetti, F.; Reale, A. Fully-sprayed flexible polymer solar cells with a cellulose-graphene electrode. Mater. Today Energy 2018, 7, 105-112. [CrossRef]

4. Apostolopoulou, A.; Sygkridou, D.; Rapsomanikis, A.; Kalarakis, A.; Stathatos, E. Enhanced performance of mesostructured perovskite solar cells in ambient conditions with a composite $\mathrm{TiO} 2-\mathrm{In} 2 \mathrm{O} 3$ electron transport layer. Sol. Energy Mater. Sol. Cells 2017, 166, 100-107. [CrossRef]

5. Tan, H.; Jain, A.; Voznyy, O.; Lan, X.; Arquer, F.P.G.D.; Fan, J.Z.; Bermudez, R.Q.; Yuan, M.; Zhang, B.; Zhao, Y.; et al. Efficient and stable solution-processed planar perovskite solar cells via contact passivation. Science 2017, 355, 722-726. [CrossRef] [PubMed]

6. Zhao, L.; Luo, D.; Wu, J.; Hu, Q.; Zhang, W.; Chen, K.; Liu, T.; Liu, Y.; Zhang, Y.; Liu, F.; et al. High-performance inverted planar heterojunction perovskite solar cells based on lead acetate precursor with efficiency exceeding 18\%. Adv. Funct. Mater. 2016, 26, 3508-3514. [CrossRef]

7. Malik, A.; Kandasubramanian, B. Flexible Polymeric Substrates for Electronic Applications. Polym. Rev. 2018, 58, 630-667. [CrossRef]

8. Xu, X.; Xu, Z.; Tang, J.; Zhang, X.; Zhang, L.; Wu, J.; Wu, J. High-performance planar perovskite solar cells based on low-temperature solution-processed well-crystalline $\mathrm{SnO} 2$ nanorods electron-transporting layers. Chem. Eng. J. 2018, 351, 391-398. [CrossRef]

9. Cairns, D.R.; Witte, R.P.; Sparacin, D.K.; Sachsman, S.M.; Paine, D.C.; Crawford, G.P.; Newton, R.R. Strain-dependent electrical resistance of tin-doped indium oxide on polymer substrates. Appl. Phys. Lett. 2000, 76, 1425-1427. [CrossRef]

10. Liu, Y.; Murtaza, I.; Shuja, A.; Meng, H.; Ahmed, S. Interfacial modification for heightening the interaction between PEDOT and substrate towards enhanced flexible solid supercapacitor performance. Chem. Eng. J. 2020, 379, 122326. [CrossRef]

11. Tai, Q.; Chen, B.; Guo, F.; Xu, S.; Hu, H.; Sebo, B.; Zhao, X. In Situ Prepared Transparent Polyaniline Electrode and Its Application in Bifacial Dye-Sensitized Solar Cells. ACS Nano 2011, 5, 3795-3799. [CrossRef] [PubMed]

12. Bu, C.; Tai, Q.; Liu, Y.; Guo, S.; Zhao, X. A transparent and stable polypyrrole counter electrode for dye-sensitized solar cell. J. Power Sources 2013, 221, 78-83. [CrossRef]

13. Reynaud, O.; Nasibulin, A.G.; Anisimov, A.S.; Anoshkin, I.V.; Jiang, H.; Kauppinen, E.I. Aerosol feeding of catalyst precursor for CNT synthesis and highly conductive and transparent film fabrication. Chem. Eng. J. 2014, 255, 134-140. [CrossRef]

14. Iwan, A.; Caballero-Briones, F.; Bogdanowicz, K.A.; Barceinas-Sánchez, J.D.O.; Przybyl, W.; Januszko, A.; Miranda, J.A.B.; Espinosa-Ramirez, A.P.; Guerrero-Contreras, J. Optical and electrical properties of graphene oxide and reduced graphene oxide films deposited onto glass and Ecoflex $($ substrates towards organic solar cells. Adv. Mater. Lett. 2018, 9, 58-65. [CrossRef] 
15. Cai, W.; Zhu, Y.; Li, X.; Piner, R.D.; Ruoff, R.S. Large area few-layer graphene/graphite films as transparent thin conducting electrodes. Appl. Phys. Lett. 2009, 95, 123115. [CrossRef]

16. Leem, D.-S.; Edwards, A.; Faist, M.; Nelson, J.; Bradley, D.; De Mello, J. Efficient Organic Solar Cells with Solution-Processed Silver Nanowire Electrodes. Adv. Mater. 2011, 23, 4371-4375. [CrossRef]

17. Fryń, P.; Bogdanowicz, K.A.; Górska, N.; Rysz, J.; Krysiak, P.; Marzec, M.; Marzec, M.; Iwan, A.; Januszko, A. Hybrid Materials Based on L,D-Poly(lactic acid) and Single-Walled Carbon Nanotubes as Flexible Substrate for Organic Devices. Polymers 2018, 10, 1271. [CrossRef]

18. Devarayan, K.; Lei, D.; Kim, H.Y.; Kim, B.-S. Flexible transparent electrode based on PANi nanowire/nylon nanofiber reinforced cellulose acetate thin film as supercapacitor. Chem. Eng. J. 2015, 273, 603-609. [CrossRef]

19. Jung, J.-W.; Lee, J.U.; Jo, W.H. High-Efficiency Polymer Solar Cells with Water-Soluble and Self-Doped Conducting Polyaniline Graft Copolymer as Hole Transport Layer. J. Phys. Chem. C 2009, 114, 633-637. [CrossRef]

20. Heo, S.; Baek, K.H.; Lee, T.H.; Lee, J.Y.; Moon, D.K. Enhanced performance in inverted polymer solar cells via solution process: Morphology controlling of PEDOT:PSS as anode buffer layer by adding surfactants. Org. Electron. 2013, 14, 1629-1635. [CrossRef]

21. Andreoli, E.; Liao, K.-S.; Haldar, A.; Alley, N.J.; Curran, S.A. PPy:PSS as alternative to PEDOT:PSS in organic photovoltaics. Synth. Met. 2013, 185, 71-78. [CrossRef]

22. Notarianni, M.; Vernon, K.; Chou, A.; Aljada, M.; Liu, J.; Motta, N. Plasmonic effect of gold nanoparticles in organic solar cells. Sol. Energy 2014, 106, 23-37. [CrossRef]

23. Sun, J.; Zhu, Y.; Xu, X.; Lan, L.; Zhang, L.; Cai, P.; Chen, J.; Peng, J.; Cao, Y. High Efficiency and High Voc Inverted Polymer Solar Cells Based on a Low-Lying HOMO Polycarbazole Donor and a Hydrophilic Polycarbazole Interlayer on ITO Cathode. J. Phys. Chem. C 2012, 116, 14188-14198. [CrossRef]

24. Iyer, A.; Hack, J.H.; Trujillo, D.A.; Tew, B.; Zide, J.; Opila, R.L. Effects of Co-Solvents on the Performance of PEDOT:PSS Films and Hybrid Photovoltaic Devices. Appl. Sci. 2018, 8, 2052. [CrossRef]

25. Singh, V.; Kumar, T. Study of modified PEDOT:PSS for tuning the optical properties of its conductive thin films. J. Sci. Adv. Mater. Devices 2019, 4, 538-543. [CrossRef]

26. Jäckle, S.; Liebhaber, M.; Gersmann, C.; Mews, M.; Jäger, K.; Christiansen, S.; Lips, K. Potential of PEDOT:PSS as a hole selective front contact for silicon heterojunction solar cells. Sci. Rep. 2017, 7, 2170. [CrossRef]

27. Li, Q.; Yang, J.; Chen, S.; Zou, J.; Xie, W.; Zeng, X. Highly Conductive PEDOT:PSS Transparent Hole Transporting Layer with Solvent Treatment for High Performance Silicon/Organic Hybrid Solar Cells. Nanoscale Res. Lett. 2017, 12, 506. [CrossRef]

28. Dąbczyński, P.; Marzec, M.; Pięta, Ł.; Fijałkowski, K.; Raczkowska, J.; Bernasik, A.; Budkowski, A.; Rysz, J. Engineering a Poly(3,4-ethylenedioxythiophene):(Polystyrene Sulfonate) Surface Using Self-Assembling Molecules-A Chemical Library Approach. ACS Omega 2018, 3, 3631-3639.

29. Mahato, S.; Gerling, L.G.; Voz, C.; Alcubilla, R.; Puigdollers, J. PEDOT:PSS as an Alternative Hole Selective Contact for ITO-Free Hybrid Crystalline Silicon Solar Cell. IEEE J. Photovoltaics 2016, 6, 934-939. [CrossRef]

30. Koushik, D.; Verhees, W.J.H.; Kuang, Y.; Veenstra, S.; Creatore, M.; Schropp, R.E.; Zhang, N. Atomic Layer Deposition Enabled Perovskite/PEDOT Solar Cells in a Regular n-i-p Architectural Design. Adv. Mater. Interfaces 2017, 4, 1700043. [CrossRef]

31. Broski, A.; Guo, Y.; Khan, W.A.; Li, W. Characteristics of PEDOT:PSS thin films spin-coated on ITO. In Proceedings of the 2017 IEEE 12th International Conference on Nano/Micro Engineered and Molecular Systems (NEMS), Los Angeles, CA, USA, 9-12 April 2017; pp. 243-247.

32. Lim, K.; Jung, S.; Kim, J.-K.; Kang, J.-W.; Kim, J.-H.; Choa, S.-H.; Kim, D.-G. Flexible PEDOT: PSS/ITO hybrid transparent conducting electrode for organic photovoltaics. Sol. Energy Mater. Sol. Cells 2013, 115, 71-78. [CrossRef]

33. Girtan, M.; Rusu, M. Role of ITO and PEDOT:PSS in stability/degradation of polymer:fullerene bulk heterojunctions solar cells. Sol. Energy Mater. Sol. Cells 2010, 94, 446-450. [CrossRef]

34. Ma, S.; Qiao, W.; Cheng, T.; Zhang, B.; Yao, J.; Alsaedi, A.; Hayat, T.; Ding, Y.; Tan, Z.; Dai, S. Optical-Electrical-Chemical Engineering of PEDOT:PSS by Incorporation of Hydrophobic Nafion for Efficient and Stable Perovskite Solar Cells. ACS Appl. Mater. Interfaces 2018, 10, 3902-3911. [CrossRef] [PubMed] 
35. Vasanth, A.; Sreekala, C.O.; Sreelatha, K.S.; Jinchu, I. Micro contact printed PEDOT: PSS as cathode in dye sensitized solar cells. In Proceedings of the 2017 International Conference on Technological Advancements in Power and Energy (TAP Energy), Kollam, India, 21-23 December 2017; pp. 1-5.

36. Różycka, A.; Bogdanowicz, K.A.; Górska, N.; Rysz, J.; Marzec, M.; Iwan, A.; Pich, R.; Januszko, A. Influence of $\mathrm{TiO} 2$ Nanoparticles on Liquid Crystalline, Structural and Electrochemical Properties of (8Z)-N-(4-((Z)-(4-pentylphenylimino)methyl) benzylidene)-4-pentylbenzenamine. Materials 2019, 12, 1097. [CrossRef]

37. Drioli, E.; Criscuoli, A.; Curcio, E. (Eds.) Membrane Science and Technology. In Membrane Materials; Elsevier: San Diago, CA, USA; Elsevier: Oxford/London, UK, 2006; Chapter 2; pp. 11-104. ISSN 0927-5193.

38. Hede, P.D.; Bach, P.; Jensen, A.D. Two-fluidsprayatomisationandpneumaticnozzlesfor fluidbedcoating/agglomeration purposes: A review. Chem. Eng. Sci. 2008, 63, 3821-3842. [CrossRef]

39. Marzocchi, M.; Gualandi, I.; Calienni, M.; Zironi, I.; Scavetta, E.; Castellani, G.; Fraboni, B. Physical and Electrochemical Properties of PEDOT:PSS as a Tool for Controlling Cell Growth. ACS Appl. Mater. Interfaces 2015, 7, 17993-18003. [CrossRef]

40. Chung, D.Y.; Lee, K.J.; Sung, Y.-E. Methanol Electro-Oxidation on the Pt Surface: Revisiting the Cyclic Voltammetry Interpretation. J. Phys. Chem. C 2016, 120, 9028-9035. [CrossRef]

(C) 2020 by the authors. Licensee MDPI, Basel, Switzerland. This article is an open access article distributed under the terms and conditions of the Creative Commons Attribution (CC BY) license (http://creativecommons.org/licenses/by/4.0/). 